\title{
Personalised Single-Pill Combination Therapy in Hypertensive Patients: An Update of a Practical Treatment Platform
}

\author{
Massimo Volpe ${ }^{1,2}$ (1) $\cdot$ Giuliano Tocci $^{1,2} \cdot$ Alejandro de la Sierra $^{3} \cdot$ Reinhold Kreutz $^{4,5,6,7}$. \\ Stéphane Laurent ${ }^{8} \cdot$ Athanasios J. Manolis $^{9} \cdot$ Kostantinos Tsioufis $^{10}$
}

Received: 6 September 2017/Accepted: 2 October 2017/Published online: 31 October 2017

(c) The Author(s) 2017. This article is an open access publication

\begin{abstract}
Despite the improvements in the management of hypertension during the last three decades, it continues to be one of the leading causes of cardiovascular morbidity and mortality worldwide. Effective and sustained reductions in blood pressure (BP) reduce the incidence of myocardial infarction, stroke, congestive heart failure and cardiovascular death. However, the proportion of patients who achieve the recommended BP goal $(<140 / 90 \mathrm{mmHg})$ is persistently low, worldwide. Poor adherence to therapy, complex therapeutic regimens, clinical inertia, drug-related adverse events and multiple risk factors or comorbidities contribute to the disparity between the potential and actual BP control rate. Previously we published a practical therapeutic platform for the treatment of hypertension based on clinical evidence, guidelines, best practice and clinical experience. This platform provides a personalised treatment approach and can be used to improve BP control and
\end{abstract}

Electronic supplementary material The online version of this article (doi:10.1007/s40292-017-0239-7) contains supplementary material, which is available to authorized users.

Massimo Volpe

massimo.volpe@uniroma1.it

1 Division of Cardiology, Department of Clinical and Molecular Medicine, Faculty of Medicine and Psychology, Sant'Andrea Hospital, University of Rome Sapienza, Via di Grottarossa 1035-39, 00189 Rome, Italy

2 IRCCS Neuromed, Via Atinense, 18, 86077 Pozzilli, Isernia, Italy

3 Department of Internal Medicine, Hospital Mútua Terrassa, University of Barcelona, Plaça del Doctor Robert, 5, 08221, Terrassa, Barcelona, Spain

4 Department of Clinical Pharmacology and Toxicology, Charité, Universitätsmedizin Berlin, 10117 Berlin, Germany simplify treatment. It uses long-acting, effective and welltolerated angiotensin receptor blocker (ARB) olmesartan, in combination with a calcium channel blocker amlodipine, and/or a thiazide diuretic hydrochlorothiazide. These drugs were selected based on the availability in most European Countries of single-pill, fixed formulations in a wide range of doses for both dual- and triple-drug combinations. The platform approach could be applied to other ARBs or angiotensin-converting enzyme inhibitors available in single-pill, fixed-dose combinations. Here, we present an update, which takes into account the results of the recently published studies and extends the applicability of the platform to common conditions that are often neglected or poorly considered in clinical practice guidelines.

Keywords Antihypertensive therapy - Angiotensin receptor blockers - Angiotensin-converting enzyme inhibitors - Calcium channel blockers · Hypertension . Olmesartan medoxomil

5 Corporate Member of Freie Universität Berlin, Berlin, Germany

6 Humboldt-Universität zu Berlin, Berlin, Germany

7 Berlin Institute of Health, Berlin, Germany

8 Department of Pharmacology and INSERM U 970, European Georges Pompidou Hospital, Université Paris-Descartes and Assistance Publique Hôpitaux de Paris, 56 rue Leblanc, 75015 Paris, France

9 Department of Cardiology, Asclepeion General Hospital, Athens, Greece

10 Hippokration Hospital, National and Kapodistrian University of Athens, Vas Sofias 114, 11527 Athens, Greece 


\section{Introduction}

Hypertension is the most frequent cardiovascular risk factor and strongly contributes to the development and progression of major cardiovascular and cerebrovascular events. Elevated blood pressure (BP) is associated with an increased risk of myocardial infarction, stroke, congestive heart failure and cardiovascular death, independently of age, gender and comorbidities [1]. A meta-analysis of randomised clinical trials has convincingly demonstrated the beneficial effects of lowering BP below 140/90 $\mathrm{mmHg}$ [2]. Achievement of this target reduces risk of developing hypertension-related complications and cardiovascular death. At present, a large number of antihypertensive drugs from different classes are available and detailed clinical practice guidelines for the treatment of hypertension are published regularly. Nevertheless, in many patients, hypertension is not satisfactorily controlled [3].

Several explanations of this discrepancy are possible, including poor adherence to prescribed therapy, complex therapeutic regimens (heavy pill burden), reluctance to intensify therapy (clinical inertia), drug-related adverse events (discontinuations) and presence of multiple risk factors and comorbidities. In addition, many hypertensive patients are treated with a single-drug regimen, despite the fact that less than one third of patients on monotherapy achieve BP control, and most require a combination of at least two antihypertensive drugs [4]. Another cause of poor adherence is the failure to achieve treatment benefits rapidly. This is often the result of adopting the same or similar therapeutic strategy in different patients. However, as many physicians who deal with it would attest, in hypertension, as in many other clinical conditions, the "one size fits all" approach does not work.

International clinical practice guidelines for the treatment of hypertension recommend that patients who are at high cardiovascular risk, as well as those who require a reduction of more than $20 \mathrm{mmHg}$ in systolic $\mathrm{BP}$ and more than $10 \mathrm{mmHg}$ in diastolic BP in order to meet the target level of $140 / 90 \mathrm{mmHg}$, may benefit from initiating treatment with a two-drug combination therapy [5]. This strategy is emphasized in other international guidelines, especially those produced in the US [6] and Canada [7, 8]. According to this approach, failure to achieve BP control with a two-drug combination at full dose may require switching to a different two-drug combination or the addition of a third drug [5-10]. When compared with the traditional method, the approach that aimed to achieve high rates of BP control (more than $70 \%$ of patients) resulted in reduction in the number of deaths from myocardial infarction and stroke in over 500,000 patients [11].

\section{Background}

In order to help physicians for achieving the following results in their clinical practice: (1) simplify therapy; (2) overcome therapeutic inertia; and (3) promote the achievement of the recommended BP targets, we recently proposed a platform for prescribing single-pill, dual- or triple-drug, fixed-dose combination therapies that takes into account the presence of various risk factors, markers of organ damage and comorbidities, as well as the grade of hypertension [12].

In designing this platform, we took into account the fact that the only triple therapy combination recommended by clinical practice guidelines for the treatment of hypertension consists of a renin-angiotensin system (RAS) blocking agent, a calcium channel blocker (CCB) and a thiazide diuretic. In particular, we selected a strategy based on the angiotensin receptor blockers (ARBs) on the basis of their excellent tolerability profile and high rates of adherence [13-15]. Furthermore, ARBs are equivalent to angiotensinconverting enzyme (ACE) inhibitors in terms of their efficacy [16, 17] and cardioprotective properties [18]. We designed the platform around an ARB olmesartan (OLM), because at the time we proposed the first treatment platform, it was available in multiple single-pill, fixed-dose, triple-therapy combinations with amlodipine (AML) and hydrochlorothiazide (HCTZ) [19]. These combinations have a long-lasting effect on BP and a good tolerability profile, with a low incidence of drug-related adverse events and discontinuations [20, 21]. These effects have been demonstrated in numerous clinical trials performed in hypertensive outpatients at different cardiovascular risk profile. The fact that each individual component is available in a wide variety of doses provides flexibility for upor down-titration. The same approach could be used with other ARBs that are available for the management of hypertension, as well as for ACE inhibitors that are effective over a 24-h period, to allow for once-a-daily, single-pill administration [22-24].

Effective management of hypertension remains a pressing concern due to the continually rising prevalence of this condition in the general population and the growing number of patients with cardiovascular and non-cardiovascular comorbidities. For these reasons, we have produced an update to the treatment platform for the management of hypertension, which takes into account the results of the recently published randomised clinical trials. The update also extends the applicability of the platform to conditions that are common in the clinical practice, but often neglected or poorly considered in guidelines. 


\section{Platform organisation}

The method that were used to create the platform has been described previously [12]. Briefly, the platform is neither an algorithm nor a guideline, but an attempt to apply evidencebased medicine, when available, to the management of hypertension in routine clinical practice [12]. The platform also proposes best practice solutions for the types of patients who are poorly represented in randomised clinical trials, or for whom no clinical practice guidelines recommendations are available. This approach is not intended to replace ongoing therapy for clinical conditions and comorbidities that require specific drug treatments. Furthermore, effective therapy that allows the patient to achieve the recommended BP targets should not be replaced. Instead, the platform represents an attempt to help physicians better control hypertension, and should be considered as an educational advice or a "secondo opinion" [25-29]. Therefore, it is important to consider compatibility with existing therapy for underlying conditions. The referring physician must determine the appropriate therapy and dosage for individual hypertensive patients, as recommended by current guidelines [5]. In addition, the platform is organised to match the intensity of therapy (defined as the recommended dosage range and type of combination) with the appropriate grade of hypertension and the global cardiovascular risk profile of an individual patient. For example, the need to achieve BP control is more urgent in patients with higher cardiovascular risk. Therefore, such patients may benefit from higher doses and/or combination therapy, potentially as the first-line treatment [5].

The first version of the platform was organised in two sections. The first section addressed patients with specific concomitant risk factors and organ damage (electronic Table 1, available online), while the second section referred to patients with associated clinical conditions that match frequent comorbidities (electronic Table 2, available online) [12]. In order to help physicians in choosing the most appropriate therapeutic regimen, we decided to maintain this approach in this update and propose two additional tables, addressing patients with uncontrolled hypertension (Table 1) and those who belong to special populations or have comorbidities (Table 2).

The structure of the tables is similar to that used in a clinical practice guideline for the management of hypertension [5]. The appropriate intensity of therapy can be determined based on the BP levels, as well as the assessment of risk factors, subclinical organ damage or clinical conditions. In the tables, the intensity of antihypertensive treatment increases from left to right, according to increasing hypertension grade [12]. Hypertensive patients with additional non-conventional risk factors may benefit from more intensive therapy and a lower threshold for further intensification [12]. The effectiveness of the selected antihypertensive therapy should be assessed after 4 to 6 weeks.

\section{Specific forms of hypertension}

The therapeutic platform proposed for a number of specific forms of hypertension is presented in Table 1.

\subsection{White-coat hypertension}

White-coat hypertension is a clinical condition characterized by above-normal BP during clinical consultations and normal BP during the 24-h ambulatory BP monitoring [30]. Clinical studies have demonstrated that, although timelimited, BP elevations recorded in this condition are associated with an increased risk of development and progression of hypertension-related organ damage, as well as with cardiovascular events [31-33]. Therefore, it is important to detect this clinical condition early, at the asymptomatic stage, if possible. Whether patients with white-coat hypertension should receive pharmacological treatment depends on individual circumstances, particularly on the level of office BP and global cardiovascular risk.

Clinical studies of OLM-based therapy have demonstrated that therapy with OLM provides effective and sustained systolic and diastolic BP reductions over the 24-h period, both as monotherapy $[34,35]$ and in combination with AML [36]. The results of a relatively large randomised clinical study have shown that the OLM/AML combination produces a greater reduction in 24-h and central BP compared with combination therapy based on an ACE inhibitor and AML [37]. In addition to the immediate vasodilatory effect, long-term administration of OLM causes remodelling of the arterial system, reducing the stiffness of large arteries and leading to further reductions in systolic BP and pulse pressure [38].

\subsection{Pseudo-resistant hypertension due to poor adherence}

Pseudo-resistant hypertension is a clinical condition in which the recommended BP targets can be achieved by addressing non-adherence to prescribed therapy and optimizing and simplifying the treatment regimen. Several diagnostic algorithms have been proposed for identifying pseudo-resistant hypertension [39-42], and several studies have demonstrated that, after excluding secondary forms of hypertension, BP can be effectively and safely lowered to targets in this group of patients [43]. 
Table 1 (a) Personalized single-pill combination therapy based on an angiotensin receptor blocker combined with either a thiazide diuretic or a calcium-channel blocker (or both) in patients with specific forms of hypertension according to individual global cardiovascular risk stratification and (b) personalized single-pill combination therapy based on an angiotensin receptor blocker combined with either a thiazide diuretic or a calcium-channel blocker (or both) in patients over 50 years old with hypertension and high cardiovascular risk (SPRINT eligible patients), according to individual global cardiovascular risk stratification

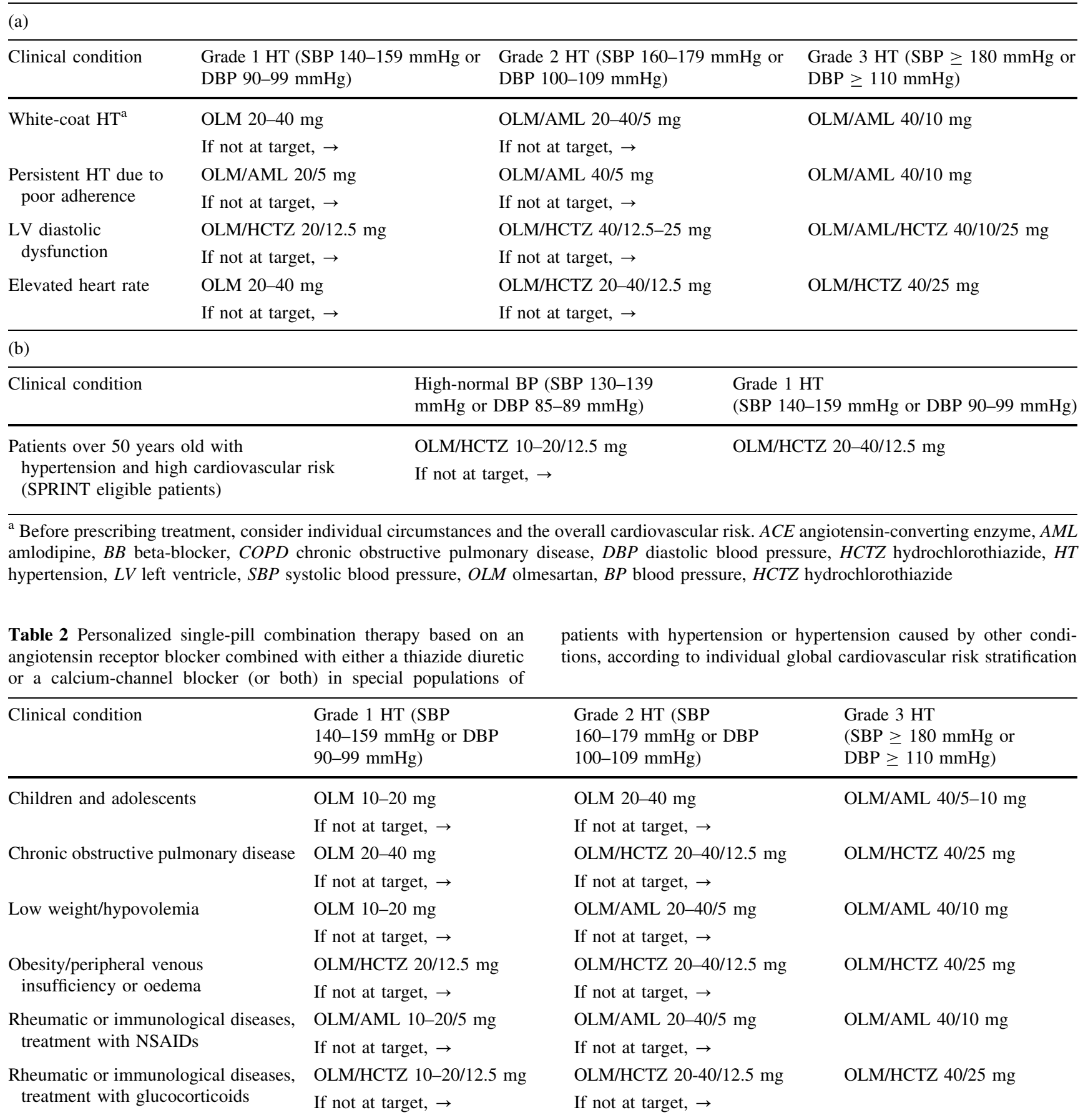

$A M L$ amlodipine, DBP diastolic blood pressure, HCTZ hydrochlorothiazide, $H T$ hypertension, $L V$ left ventricular, NSAIDS non-steroidal antiinflammatory drugs, $O L M$ olmesartan, $S B P$ systolic blood pressure 
Treatment with antihypertensive drugs is often interrupted early and spontaneously $[44,45]$. The use of singlepill combination therapy has the potential to reduce the frequency of treatment discontinuation, particularly if the components of the pill are effective throughout the day. For these reasons, the choice of an effective, well-tolerated and convenient first-line therapy is a key factor in ensuring adherence to prescribed medications.

Studies of OLM, both as monotherapy and, to a greater extent, as a component of combination therapies, have consistently demonstrated that it has a better tolerability profile than placebo and that the risk of drug-related adverse events is at least comparable to that with other ARBs and lower than with any other antihypertensive drug class, including diuretics [46-49]. Of note, the incidence of drug-related adverse events was largely independent of dose titration and was, in fact, lower when the drug was used in fixed-dose combination therapies with HCTZ, AML or both [46-49]. In addition, a recent randomised, double-blind, controlled clinical study demonstrated the non-inferiority of the fixed-dose combination of OLM and AML to the combination of perindopril and AML in reducing diastolic BP after 24 weeks of treatment and after a missed dose $(-11.7$ and $-10.5 \mathrm{mmHg}$, respectively) $[50,51]$.

\subsection{Left ventricular diastolic dysfunction}

Left ventricular (LV) diastolic dysfunction is a common condition in hypertensive patients, with or without evidence of structural cardiac organ damage, such as LV hypertrophy. Although this condition has not been recognised in the current guidelines as a marker of hypertensionrelated organ damage [5], some studies have demonstrated its association with the risk of developing mitral regurgitation, atrial fibrillation, pulmonary oedema and congestive heart failure [52, 53].

Antihypertensive therapies based on RAS blockers, $\mathrm{CCBs}$ and diuretics have been shown to reduce the incidence of new-onset heart failure in different clinical settings across the cardiovascular continuum, proving that effective BP control is the cornerstone of any preventive strategy aimed at reducing the occurrence of such complication [54-56]. In hypertensive patients who are at high cardiovascular risk, diuretics are the most effective class of drugs for preventing heart failure, followed by RAS inhibitors [57]. Therefore, we suggest that early use of singlepill combination therapy with HCTZ should be considered in patients with grade 2 hypertension and early electrocardiographic or echocardiographic markers of diastolic dysfunction.

\subsection{Elevated heart rate}

Physicians frequently encounter patients with an elevated heart rate in routine clinical practice. This condition is often the result of sympathetic over-activity and, in hypertensive patients, it has been associated with a high risk of complications $[58,59]$. Elevated heart rate is often successfully managed with the use of beta-blockers. The combination with thiazide diuretics is preferred in patients with uncontrolled hypertension who require combination therapy, but are intolerant of beta-blockers, or for whom they are contraindicated, because vasodilating drugs, including CCBs, may cause reflex activation of the sympathetic nervous system and tachycardia.

\subsection{Patients over 50 years old with hypertension and high cardiovascular risk (SPRINT eligible)}

The Systolic Blood Pressure Intervention Trial (SPRINT) was a large, randomised, controlled clinical study that was performed in the US under the auspices of the National Institutes of Health (NIH). The aim of the study was to explore the effects of lowering systolic BP to less than $120 \mathrm{mmHg}$ (intensive treatment arm) on the risk of major cardiovascular events compared with the conventional systolic BP target of less than $140 \mathrm{mmHg}$ (conventional treatment arm) [60]. The study included hypertensive patients aged more than 50 years, with no history of diabetes or stroke, but who had a high cardiovascular risk, defined as one or more of the following items: clinical or subclinical cardiovascular disease other than stroke, chronic kidney disease with an estimated glomerular filtration rate of between 20 and $60 \mathrm{ml} / \mathrm{min} / 1.73 \mathrm{~m}^{2}$ and $\mathrm{a} \geq 15 \%$ 10-year risk of cardiovascular disease, as measured by the Framingham risk score [61]. In order to achieve early and sustained reductions in BP, patients in the intensive treatment arm were systematically treated with additional diuretics. At the end of the observational period, the frequency of major cardiovascular events, (heart failure and cardiovascular and non-cardiovascular death) was significantly lower in patients in the intensive treatment arm compared with those in the conventional treatment arm [60]. However, the generalizability of the results of the SPRINT study is undermined by the criticisms that have been levelled against its methods, in particular, the way BP was measured, which has been characterised as imprecise.

It has been estimated that hypertensive patients over 50 years old, who have a high risk of cardiovascular complications, comprise approximately $20-30 \%$ of the entire population of people with hypertension [62]. A pharmacological strategy based on OLM may be effective in managing hypertension in this cohort because of its 
pharmacodynamic characteristics (i. e. high affinity and strong binding to the AT1 subtype of angiotensin II receptors, and the greater reductions in systolic BP that can be obtained after dose titration, with or without diuretics) [62].

\section{Hypertension in special populations or caused by other conditions}

The therapeutic platform proposed for these patient populations is presented in Table 2 .

\subsection{Children and adolescents}

Observational studies and epidemiological surveys have shown that the incidence of hypertension in children and adolescents has increased over the last several decades, and that hypertension now affects a higher proportion of individuals under 18 years old, primarily in Western and industrialised countries. Several factors are believed to be implicated in this phenomenon, including genetic predisposition (family history of hypertension), high salt intake, poor diet and limited physical activity. Early reduction of elevated BP may be an effective therapeutic approach in this population and may help to reduce the burden of hypertension-related cardiovascular disease in the future.

In the past, due to the absence of prospective, long-term, randomised, controlled clinical trials in young individuals with hypertension, lifestyle changes were often considered to be the only strategy for reducing high BP [63]. More recently, clinical data on the efficacy and safety of the five major classes of antihypertensive drugs have become available. In particular, a clinical study has demonstrated the efficacy and safety of OLM in children and adolescents with hypertension [64]. On the other hand, long-term use of diuretics in this group of patients may lead to deterioration of renal function and is, therefore, not recommended.

\subsection{Chronic obstructive pulmonary disease}

Co-occurrence of hypertension and chronic obstructive pulmonary disease (COPD) is relatively common [65]. In this subset of hypertensive patients, the presence of cardiac adaptations, primarily hypertrophy and/or dysfunction of both ventricles, may promote the development and progression of effort dyspnoea, hypoxygenation, pulmonary congestion and congestive heart failure.

Descriptions of therapeutic goals and BP targets for patients with hypertension and COPD are currently lacking. The only exception is a newsletter of the European Society of Hypertension (ESH) published in 2012 [66]. This document proposes that the therapeutic goals in hypertensive patients with COPD should be reduction of long-term pulmonary function decline, prevention and treatment of exacerbations, reduction of hospitalisations and mortality, relief of disabling dyspnoea and improvement of exercise tolerance and health-related quality of life [66]. The proposed goals of antihypertensive treatment include normalisation of BP, prevention of cardiovascular morbidity and mortality, extension of lifespan and improvement of the quality of life [66]. The fact that the majority of antihypertensive drugs can affect airway function complicates the treatment of hypertension in patients with COPD. RAS inhibitors, including ACE inhibitors and ARBs, are preferred, despite the fact that only limited data are available [67-69]. Depending on the haemodynamic profile and the presence of tachycardia and/ or pulmonary hypertension, as well as the tendency to develop right-heart failure, a combination therapy with thiazide diuretics may be useful.

\subsection{Low weight/hypovolemia}

While the high prevalence of overweight or obesity are frequent in clinical studies of patients with hypertension, and the impact of these conditions on BP is recognized, the potential effect of low body weight or hypovolemia has often been neglected or insufficiently considered. There are subgroups of high-risk patients with hypertension, such as individuals of advanced age (e.g. octogenarians), those with neurological (e.g. severe cognitive impairment or Alzheimer's disease) or psychiatric disorders (e.g. anorexia) or those with end-stage chronic illness (e.g. cachexia, solid tumours or cancers), in which high peripheral vascular resistance and accelerated atherosclerotic disease of large arteries may lead to the development of hypertension in the presence of hypovolemic status. This may increase the risk of symptomatic hypotension, renal failure, neurological deterioration and syncope. For this reason, it may be useful to adopt a therapeutic regimen characterized by sustained and consistent antihypertensive efficacy over the period of 24 hours, thus avoiding abnormal BP variations and reducing the risk of complications due to hypotension. Therefore, combination therapies with CCBs are recommended, while diuretics should be avoided.

\subsection{Obesity/peripheral venous insufficiency}

Central or visceral obesity is frequently associated with essential hypertension and markedly increases the risk of developing metabolic syndrome, dyslipidaemia, new-onset diabetes and cardiovascular disease. This risk is further increased by concomitant use of some beta-blockers in combination with medium-to-high dose diuretics [70-72]. 
In addition, dihydropyridinic CCBs, including AML, promote lower-limb oedema, mostly in female patients with venous insufficiency and obesity. Therefore, a predisposition to venous insufficiency or lower-limb oedema, is a contra-indication for the use of CCBs, including in combination therapy. On the other hand, combination therapy with an ARB or an ACE inhibitor with low-dose HCTZ is the recommended treatment in such patients.

\subsection{Rheumatic and immunological diseases}

Patients with rheumatic diseases have been systematically excluded from randomised, controlled clinical trials conducted in hypertension, as well as other cardiovascular conditions, and, therefore, definitive evidence of the therapeutic efficacy and safety of many antihypertensive treatments in this high-risk population is lacking. Rheumatic and immunological diseases are characterised by life-long symptoms and increased levels of systemic and local inflammation. This may promote rapid and aggressive atherosclerotic and arteriosclerotic disease, as well as lead to pro-coagulative status and increased peripheral vascular resistance and arterial stiffness [73-75]. For these reasons, the incidence of cardiovascular complications, primarily atrial fibrillation and other arrhythmias, coronary artery disease, myocardial infarction, ischemic stroke and congestive heart failure, is relatively high in patients with rheumatic and immunological conditions. The use of nonsteroidal anti-inflammatory drugs or glucocorticoids may necessitate the use of $\mathrm{CCB}$ and diuretic combination therapies to control blood pressure [76]. Because the therapeutic regimens necessary to treat rheumatic and immunological conditions are often complex, a fixed combination therapy, administered once daily and consisting of a combination of a long-lasting ARB and AML, may be well suited for reducing the risk of cardiovascular complications. In patients exposed to long-term treatment with non-steroidal anti-inflammatory drugs, who are more susceptible to developing renal dysfunction or chronic renal failure, the use of diuretics may exacerbate renal impairment and is, therefore, not recommended. In contrast, in patients undergoing long-term treatment with steroids, a combination with thiazide diuretics is preferable.

In chronic conditions which require complex long-term treatment regimens, several reports described hypertension due to the use of anti-neoplastic or anti-vascular growth factor monoclonal antibodies. These drugs have been shown to induce vessel rarefaction and increased peripheral vascular resistance. In such conditions, the use of use of single-pill combination therapies based on CCBs is recommended.

\section{Conclusions}

Effective and well-tolerated single-pill, dual- or tripledrug, fixed dose combination therapies have the potential to greatly improve BP control and close the gap between the promising results of interventional trials and the often disappointing data from routine clinical practice. An approach aiming to determine the appropriate therapeutic intensity based on concomitant conditions may help physicians design personalised treatment strategies. When applied as part of a comprehensive approach that includes regular follow-up and timely therapy intensification, it may also increase the proportion of patients with hypertension who achieve the recommended BP targets, thus reducing the burden of hypertension-related cardiovascular, cerebrovascular and renal diseases.

Acknowledgements The authors would like to thank Georgii Filatov, of Springer Healthcare Communications, who performed an English edit of this manuscript. This medical writing assistance was funded by Menarini International Operations Luxembourg S.A. (MIOL).

\section{Compliance with ethical standards}

Funding Expert review of the manuscript has been funded by Menarini International Operations Luxembourg S.A. (MIOL).

Conflict of interest Massimo Volpe served on international advisory boards of Daiichi Sankyo Europe, and lectured in symposia supported by Daiichi Sankyo Europe, Menarini International, Merck, Servier, Laboratori Guidotti and Malesci. Giuliano Tocci lectured in symposia supported by Merck, Servier, Menarini International, Malesci and Laboratori Guidotti. Alejandro de la Sierra lectured in symposia supported by Abbott, Daiichi-Sankyo, Menarini and Pfizer. Reinhold Kreutz received honoraria for consultancy, lectures and support for research during the last 3 years from AstraZeneca, Bayer AG, BerlinChemie Menarini, Bristol-Myers Squibb, Daiichi Sankyo, Lundbeck, Sanofi and Servier. Stephane Laurent has received grants, honoraria as speakeror chairman, or consultation fees for advisory board from Astra-Zeneca, Bayer-Schering, Boehringer-Ingelheim, Chiesi, Daichi-Sankyo, Esaote, Menarini, Negma, Novartis, Recordati, and Servier. Athanasios J. Manolis lectured in symposia supported by SERVIER, Bayer, Menarini, Ferrer, Recordati. Costas Tsioufis declares consultancy, Research Grant or honoraria fees from Servier, Menarini Int, Medtronic, Bayer, Novartis, Astra-Zeneca, Boehringer In, Pfizer, Chiesi, Recordati, Sanofi, MSD.

Ethical approval This article does not contain data derived from studies with human participants performed by any of the authors. The clinical studies referred in the text received relevant ethical approval.

Open Access This article is distributed under the terms of the Creative Commons Attribution-NonCommercial 4.0 International License (http://creativecommons.org/licenses/by-nc/4.0/), which permits any noncommercial use, distribution, and reproduction in any medium, provided you give appropriate credit to the original author(s) and the source, provide a link to the Creative Commons license, and indicate if changes were made. 


\section{References}

1. Rapsomaniki E, Timmis A, George J, Pujades-Rodriguez M, Shah AD, Denaxas S, et al. Blood pressure and incidence of twelve cardiovascular diseases: lifetime risks, healthy life-years lost, and age-specific associations in 1.25 million people. Lancet. 2014;383(9932):1899-911.

2. Ettehad D, Emdin CA, Kiran A, Anderson SG, Callender T, Emberson J, et al. Blood pressure lowering for prevention of cardiovascular disease and death: a systematic review and metaanalysis. Lancet. 2016;387(10022):957-67.

3. Danaei G, Finucane MM, Lin JK, Singh GM, Paciorek CJ, Cowan MJ, et al. National, regional, and global trends in systolic blood pressure since 1980: systematic analysis of health examination surveys and epidemiological studies with 786 countryyears and 5.4 million participants. Lancet. 2011;377(9765):568-77.

4. Volpe M, Rosei EA, Ambrosioni E, Cottone S, Cuspidi C, Borghi C, et al. 2012 consensus document of the Italian Society of Hypertension (SIIA): strategies to improve blood pressure control in Italy: from global cardiovascular risk stratification to combination therapy. High Blood Press Cardiovasc Prev. 2013;20(1):45-52.

5. Mancia G, Fagard R, Narkiewicz K, Redon J, Zanchetti A, Bohm $\mathrm{M}$, et al. $2013 \mathrm{ESH} / \mathrm{ESC}$ guidelines for the management of arterial hypertension: the Task Force for the Management of Arterial Hypertension of the European Society of Hypertension (ESH) and of the European Society of Cardiology (ESC). Eur Heart J. 2013;34(28):2159-219.

6. James PA, Oparil S, Carter BL, Cushman WC, Dennison-Himmelfarb C, Handler J, et al. 2014 evidence-based guideline for the management of high blood pressure in adults: report from the panel members appointed to the Eighth Joint National Committee (JNC 8). JAMA. 2014;311(5):507-20.

7. Myers MG, Tobe SW. A Canadian Perspective on the Eighth Joint National Committee (JNC 8) Hypertension Guidelines. J Clin Hypertens (Greenwich). 2014;16(4):246-8.

8. Leung AA, Nerenberg K, Daskalopoulou SS, McBrien K, Zarnke KB, Dasgupta K, et al. Hypertension Canada's 2016 Canadian Hypertension Education Program Guidelines for blood pressure measurement, diagnosis, assessment of risk, prevention, and treatment of hypertension. Can J Cardiol. 2016;32(5):569-88.

9. Chobanian AV, Bakris GL, Black HR, Cushman WC, Green LA, Izzo JL Jr, et al. Seventh report of the joint national committee on prevention, detection, evaluation, and treatment of high blood pressure. Hypertension. 2003;42(6):1206-52.

10. Feldman RD, Zou GY, Vandervoort MK, Wong CJ, Nelson SA, Feagan BG. A simplified approach to the treatment of uncomplicated hypertension: a cluster randomized, controlled trial. Hypertension. 2009;53(4):646-53.

11. Campbell NR, Brant R, Johansen H, Walker RL, Wielgosz A, Onysko $\mathrm{J}$, et al. Increases in antihypertensive prescriptions and reductions in cardiovascular events in Canada. Hypertension. 2009;53(2):128-34.

12. Volpe M, de la Sierra A, Kreutz R, Laurent S, Manolis AJ. ARBbased single-pill platform to guide a practical therapeutic approach to hypertensive patients. High Blood Press Cardiovasc Prev. 2014;21(2):137-47.

13. Scholze J, Schaefer A, Kreutz R. Safety and efficacy of olmesartan: an observational pooled-analysis of 156,682 hypertensive patients. Expert Opin Drug Saf. 2011;10(2):185-96.

14. Messerli FH, Bangalore S. Angiotensin receptor blockers reduce cardiovascular events, including the risk of myocardial infarction. Circulation. 2017;135(22):2085-7.
15. Mazzaglia G, Ambrosioni E, Alacqua M, Filippi A, Sessa E, Immordino $\mathrm{V}$, et al. Adherence to antihypertensive medications and cardiovascular morbidity among newly diagnosed hypertensive patients. Circulation. 2009;120(16):1598-605.

16. Investigators O, Yusuf S, Teo KK, Pogue J, Dyal L, Copland I, et al. Telmisartan, ramipril, or both in patients at high risk for vascular events. N Engl J Med. 2008;358(15):1547-59.

17. Thomopoulos C, Parati G, Zanchetti A. Effects of blood pressurelowering on outcome incidence in hypertension: 5. Head-to-head comparisons of various classes of antihypertensive drugsoverview and meta-analyses. J Hypertens. 2015;33(7):1321-41.

18. Borghi C, Force ST, Rossi F, Force SIFT. Role of the reninangiotensin-aldosterone system and its pharmacological inhibitors in cardiovascular diseases: complex and critical issues. High Blood Press Cardiovasc Prev. 2015;22(4):429-44.

19. Volpe M, Trimarco B. A novel molecule of the angiotensin II receptor blocker class: focus on olmesartan medoxomil. High Blood Press Cardiovasc Prev. 2005;12(2):79-89.

20. Tocci G, Paneni F, Passerini J, Volpe M. Triple combination therapy to improve blood pressure control: experience with olmesartan-amlodipine-hydrochlorothiazide therapy. Expert Opinion Pharmacother. 2012;13(18):2687-97.

21. Kreutz R, Ammentorp B, Laeis P, de la Sierra A. Efficacy and tolerability of triple-combination therapy with olmesartan, amlodipine, and hydrochlorothiazide: a subgroup analysis of patients stratified by hypertension severity, age, sex, and obesity. J Clin Hypertens. 2014;16(10):729-40.

22. Karpov YA, Gorbunov VM, Deev AD. Effectiveness of fixeddose perindopril/amlodipine on clinic, ambulatory and selfmonitored blood pressure and blood pressure variability: an openlabel, non comparative study in the general practice. High Blood Press Cardiovasc Prev. 2015;22:417-25.

23. Mancia G, Asmar R, Amodeo C, Mourad JJ, Taddei S, Gamba MA, et al. Comparison of single-pill strategies first line in hypertension: perindopril/amlodipine versus valsartan/amlodipine. J Hypertens. 2015;33(2):401-11.

24. Nagy VL. Twenty-four-hour ambulatory blood pressure reduction with a perindopril/amlodipine fixed-dose combination. Clin Drug Investig. 2013;33(7):469-76.

25. Volpe M, Brommer P, Haag U, Miele C. Efficacy and tolerability of olmesartan medoxomil combined with amlodipine in patients with moderate to severe hypertension after amlodipine monotherapy: a randomized, double-blind, parallel-group, multicentre study. Clin Drug Investig. 2009;29(1):11-25.

26. Volpe M, Miele C, Haag U. Efficacy and safety of a stepped-care regimen using olmesartan medoxomil, amlodipine and hydrochlorothiazide in patients with moderate-to-severe hypertension: an open-label, long-term study. Clin Drug Investig. 2009;29(6):381-91.

27. Volpe M, Christian Rump L, Ammentorp B, Laeis P. Efficacy and safety of triple antihypertensive therapy with the olmesartan/ amlodipine/hydrochlorothiazide combination. Clin Drug Investig. 2012;32(10):649-64.

28. Chrysant SG, Izzo JL Jr, Kereiakes DJ, Littlejohn T 3rd, Oparil S, Melino M, et al. Efficacy and safety of triple-combination therapy with olmesartan, amlodipine, and hydrochlorothiazide in study participants with hypertension and diabetes: a subpopulation analysis of the TRINITY study. J Am Soc Hypertens. 2012;6(2):132-41.

29. Lewin AJ, Kereiakes DJ, Chrysant SG, Izzo JL Jr, Oparil S, Lee $\mathrm{J}$, et al. Triple-combination treatment with olmesartan medoxomil/amlodipine/hydrochlorothiazide in Hispanic/Latino patients with hypertension: the TRINITY study. Ethnicity Disease. 2014;24(1):41-7. 
30. Mancia G, Zanchetti A. White-coat hypertension: misnomers, misconceptions and misunderstandings. What should we do next? J Hypertens. 1996;14(9):1049-52.

31. Stabouli S, Kotsis V, Toumanidis S, Papamichael C, Constantopoulos A, Zakopoulos N. White-coat and masked hypertension in children: association with target-organ damage. Pediatric Nephrol. 2005;20(8):1151-5.

32. Tomiyama M, Horio T, Yoshii M, Takiuchi S, Kamide K, Nakamura S, et al. Masked hypertension and target organ damage in treated hypertensive patients. Am J Hypertens. 2006;19(9):880-6.

33. Kotsis V, Stabouli S, Toumanidis S, Papamichael C, Lekakis J, Germanidis G, et al. Target organ damage in "white coat hypertension" and "masked hypertension". Am J Hypertens. 2008;21(4):393-9.

34. Omboni S, Malacco E, Mallion JM, Volpe M, Zanchetti A, Study Group. Twenty-four hour and early morning blood pressure control of olmesartan vs. ramipril in elderly hypertensive patients: pooled individual data analysis of two randomized, double-blind, parallel-group studies. J Hypertens. 2012;30(7):1468-77.

35. Omboni S, Malacco E, Mallion JM, Volpe M. Antihypertensive efficacy and safety of olmesartan medoxomil and ramipril in elderly mild to moderate essential hypertensive patients with or without metabolic syndrome: a pooled post hoc analysis of two comparative trials. Drugs Aging. 2012;29(12):981-92.

36. Izzo JL Jr, Chrysant SG, Kereiakes DJ, Littlejohn Iii T, Oparil S, Melino M, et al. 24-Hour efficacy and safety of triple-combination therapy with olmesartan, amlodipine, and hydrochlorothiazide: the TRINITY ambulatory blood pressure substudy. J Clin Hypertens (Greenwich). 2011;13(12):873-80.

37. Ruilope LM, Investigators SS. Fixed-combination olmesartan/ amlodipine was superior to perindopril + amlodipine in reducing central systolic blood pressure in hypertensive patients with diabetes. J Clin Hypertens (Greenwich). 2016;18(6):528-35.

38. Laurent S, Boutouyrie P. Dose-dependent arterial destiffening and inward remodeling after olmesartan in hypertensives with metabolic syndrome. Hypertension. 2014;64(4):709-16.

39. Volpe M, Rosei EA, Ambrosioni E, Cottone S, Cuspidi C, Borghi $\mathrm{C}$, et al. Renal artery denervation for treating resistant hypertension : definition of the disease, patient selection and description of the procedure. High Blood Press Cardiovasc Prev. 2012;19(4):237-44.

40. Vaclavik J, Sedlak R, Plachy M, Navratil K, Plasek J, Jarkovsky $\mathrm{J}$, et al. Addition of spironolactone in patients with resistant arterial hypertension (ASPIRANT): a randomized, double-blind, placebo-controlled trial. Hypertension. 2011;57(6):1069-75.

41. Rodilla E, Costa JA, Perez-Lahiguera F, Baldo E, Gonzalez C, Pascual JM. Spironolactone and doxazosin treatment in patients with resistant hypertension. Rev Esp Cardiol. 2009;62(2):158-66.

42. Chapman N, Dobson J, Wilson S, Dahlof B, Sever PS, Wedel H, et al. Effect of spironolactone on blood pressure in subjects with resistant hypertension. Hypertension. 2007;49(4):839-45.

43. Persu A, Jin Y, Baelen M, Vink E, Verloop WL, Schmidt B, et al. Eligibility for renal denervation: experience at 11 European expert centers. Hypertension. 2014;63(6):1319-25.

44. Corrao G, Zambon A, Parodi A, Poluzzi E, Baldi I, Merlino L, et al. Discontinuation of and changes in drug therapy for hypertension among newly-treated patients: a population-based study in Italy. J Hypertens. 2008;26(4):819-24.

45. Elley CR, Gupta AK, Webster R, Selak V, Jun M, Patel A, et al. The efficacy and tolerability of 'polypills': meta-analysis of randomised controlled trials. PLoS One. 2012;7(12):e52145.

46. Barrios V, Boccanelli A, Ewald S, Girerd X, Heagerty A, Krzesinski JM, et al. Efficacy and tolerability of olmesartan medoxomil in patients with mild to moderate essential hypertension: the OLMEBEST Study. Clin Drug Investig. 2007;27(8):545-58.

47. Chrysant SG. Safety and tolerability of an olmesartan medoxomil-based regimen in patients with stage 1 hypertension: a randomized, double-blind, placebo-controlled study. Clin Drug Investig. 2010;30(7):473-82.

48. Parati G, Ochoa JE, Ramos C, Hoshide S, Lonati L, Bilo G. Efficacy and tolerability of olmesartan/amlodipine combination therapy in patients with mild-to-severe hypertension: focus on 24-h blood pressure control. Ther Adv Cardiovasc Dis. 2010;4(5):301-13.

49. Bramlage P, Zemmrich C, Ketelhut R, Wolf WP, Fronk EM, Schmieder RE. Safety, tolerability, and efficacy of a fixed-dose combination of olmesartan $40 \mathrm{mg}$ and hydrochlorothiazide 12.5/ $25 \mathrm{mg}$ in daily practice. Vasc Health Risk Manag. 2013;9:475-83.

50. Redon J, Pichler G, Missed Dose Study G. Comparative study of the efficacy of olmesartan/amlodipine vs. perindopril/amlodipine in peripheral and central blood pressure parameters after missed dose in type 2 diabetes. Am J Hypertens. 2016;29(9):1055-62.

51. Redon J, Pichler G, Missed Dose Study G. Comparative study of the efficacy of olmesartan/amlodipine vs. perindopril/amlodipine in peripheral blood pressure after missed dose in type 2 diabetes. J Hypertens. 2016;34(2):359-67.

52. Sciarretta S, Paneni F, Palano F, Chin D, Tocci G, Rubattu S, et al. Role of the renin-angiotensin-aldosterone system and inflammatory processes in the development and progression of diastolic dysfunction. Clin Sci (Lond). 2009;116(6):467-77.

53. Zanchetti A, Cuspidi C, Comarella L, Rosei EA, Ambrosioni E, Chiariello $\mathrm{M}$, et al. Left ventricular diastolic dysfunction in elderly hypertensives: results of the APROS-diadys study. J Hypertens. 2007;25(10):2158-67.

54. Massie BM, Carson PE, McMurray JJ, Komajda M, McKelvie R, Zile MR, et al. Irbesartan in patients with heart failure and preserved ejection fraction. N Engl J Med. 2008;359(23):2456-67.

55. Lonn E, Shaikholeslami R, Yi Q, Bosch J, Sullivan B, Tanser P, et al. Effects of ramipril on left ventricular mass and function in cardiovascular patients with controlled blood pressure and with preserved left ventricular ejection fraction: a substudy of the Heart Outcomes Prevention Evaluation (HOPE) Trial. J Am Coll Cardiol. 2004;43(12):2200-6.

56. Yusuf S, Pfeffer MA, Swedberg K, Granger CB, Held P, McMurray JJ, et al. Effects of candesartan in patients with chronic heart failure and preserved left-ventricular ejection fraction: the CHARM-Preserved Trial. Lancet. 2003;362(9386):777-81.

57. Sciarretta S, Palano F, Tocci G, Baldini R, Volpe M. Antihypertensive treatment and development of heart failure in hypertension: a Bayesian network meta-analysis of studies in patients with hypertension and high cardiovascular risk. Arch Intern Med. 2011;171(5):384-94.

58. Grassi G, Seravalle G, Quarti-Trevano F, Dell'Oro R, Arenare F, Spaziani D, et al. Sympathetic and baroreflex cardiovascular control in hypertension-related left ventricular dysfunction. Hypertension. 2009;53(2):205-9.

59. Grassi G, Seravalle G, Bertinieri G, Turri C, Dell'Oro R, Stella ML, et al. Sympathetic and reflex alterations in systo-diastolic and systolic hypertension of the elderly. $\mathrm{J}$ Hypertens. 2000;18(5):587-93.

60. Group SR, Wright JT, Jr., Williamson JD, Whelton PK, Snyder JK, Sink KM, et al. A Randomized Trial of Intensive versus Standard Blood-Pressure Control. N Engl J Med. 2015 Nov 26;373(22):2103-16.

61. Lloyd-Jones DM, Wilson PW, Larson MG, Beiser A, Leip EP, D'Agostino RB, et al. Framingham risk score and prediction of 
lifetime risk for coronary heart disease. Am $\mathrm{J}$ Cardiol. 2004;94(1):20-4.

62. Ruiz-Hurtado G, Banegas JR, Sarafidis PA, Volpe M, Williams B, Ruilope LM. Has the SPRINT trial introduced a new bloodpressure goal in hypertension? Nat Rev Cardiol. 2017;14:560-6.

63. Tocci G, Volpe M. Olmesartan medoxomil for the treatment of hypertension in children and adolescents. Vasc Health Risk Manag. 2011;7:177-81.

64. Hazan L, Hernandez Rodriguez OA, Bhorat AE, Miyazaki K, Tao B, Heyrman R, et al. A double-blind, dose-response study of the efficacy and safety of olmesartan medoxomil in children and adolescents with hypertension. Hypertension. 2010;55(6):1323-30.

65. Fumagalli G, Fabiani F, Forte S, Napolitano M, Marinelli P, Palange P, et al. INDACO project: a pilot study on incidence of comorbidities in COPD patients referred to pneumology units. Multidiscip Respir Med. 2013;8(1):28.

66. Farsang C, Kiss I, Tykarski A, Narkiewicz K. Treatment of hypertension in patients with chronic obstructive pulmonary disease (COPD). Eur Soc Hypertens Sci Newsl Update Hypertens Manag. 2012;13(51):1-2.

67. Lin M, Yang YF, Lee D, Chiang HT. Comparisons of long-term effects of lisinopril vs nifedipine vs conventional therapy in the treatment of mild-to-moderate hypertension in patients with chronic obstructive pulmonary disease. Zhonghua Yi Xue Za Zhi. 1996;57(6):392-400.

68. Agostoni P, Doria E, Galli C, Tamborini G, Guazzi MD. Nifedipine reduces pulmonary pressure and vascular tone during short- but not long-term treatment of pulmonary hypertension in patients with chronic obstructive pulmonary disease. Am Rev Respir Dis. 1989;139(1):120-5.
69. Bertoli L, Fusco M, Micallef E, Busnardo I. Treatment of essential hypertension with captopril in patients with chronic obstructive pulmonary disease. J Hypertens Suppl. 1985;3(2):S153-4.

70. Bangalore S, Parkar S, Grossman E, Messerli FH. A meta-analysis of 94,492 patients with hypertension treated with beta blockers to determine the risk of new-onset diabetes mellitus. Am J Cardiol. 2007;100(8):1254-62.

71. Mancia G, Grassi G, Zanchetti A. New-onset diabetes and antihypertensive drugs. J Hypertens. 2006;24(1):3-10.

72. Verdecchia P, Angeli F, Reboldi GP, Gattobigio R. New-onset diabetes in treated hypertensive patients. Curr Hypertens Rep. 2005;7(3):174-9.

73. Zanoli L, Rastelli S, Granata A, Inserra G, Empana JP, Boutouyrie $\mathrm{P}$, et al. Arterial stiffness in inflammatory bowel disease: a systematic review and meta-analysis. J Hypertens. 2016;34(5):822-9.

74. Fan F, Galvin A, Fang L, White DA, Moore XL, Sparrow M, et al. Comparison of inflammation, arterial stiffness and traditional cardiovascular risk factors between rheumatoid arthritis and inflammatory bowel disease. $\mathrm{J}$ Inflamm (Lond). 2014;11(1):29.

75. Vlachopoulos C, Gravos A, Georgiopoulos G, Terentes-Printzios D, Ioakeimidis N, Vassilopoulos D, et al. The effect of TNF-a antagonists on aortic stiffness and wave reflections: a metaanalysis. Clin Rheumatol. 2017. doi: 10.1007/s10067-017-3657-y

76. Grosser T, Ricciotti E, FitzGerald GA. The cardiovascular pharmacology of nonsteroidal anti-inflammatory drugs. Trends Pharmacol Sci. 2017;38(8):733-48. 